\title{
Effect of a Recycling Agent on the Performance of High-RAP and High-RAS Mixtures: Field and Lab Experiments
}

Article in Journal of Materials in Civil Engineering · July 2016

DOI: 10.1061/(ASCE)MT.1943-5533.0001697

CITATIONS

0

7 authors, including:

Nam Tran

Hanoi University of Industry

20 PUBLICATIONS 72 CITATIONS

SEE PROFILE

J. Richard Willis

Auburn University

36 PUBLICATIONS 112 CITATIONS

SEE PROFILE
READS

52

Zhaoxing Xie

Auburn University

27 PUBLICATIONS 27 CITATIONS

SEE PROFILE

Mary Robbins

Ohio University

16 PUBLICATIONS 15 CITATIONS

SEE PROFILE 


\title{
Effect of a Recycling Agent on the Performance of High-RAP and High-RAS Mixtures: Field and Lab Experiments
}

\author{
Nam Tran ${ }^{1}$; Zhaoxing Xie ${ }^{2}$; Grant Julian ${ }^{3}$; Adam Taylor ${ }^{4}$; Richard Willis ${ }^{5}$; \\ Mary Robbins $^{6}$; and Shane Buchanan ${ }^{7}$
}

\begin{abstract}
Reclaimed asphalt pavement (RAP) and recycled asphalt shingles (RAS) have been increasingly used in asphalt mixtures. The use of RAP and RAS in asphalt mixtures not only reduces the consumption of virgin materials, conserves energy, and protects the environment but also improves the rutting resistance of asphalt pavements. However, as more recycled materials are used in asphalt mixtures, there is increasing concern over their potential negative effects on the mix cracking resistance. To improve the cracking resistance of asphalt mixtures with high RAP/RAS contents, one of the approaches considered is using recycling agents to potentially restore performance properties of the aged binder. This project was conducted to evaluate the effect of a recycling agent (RA), known as Hydrogreen, on the long-term field performance of high RAP and RAS mixes. The field study consisted of three test sections, each constructed by placing a dense-graded surface lift at a depth of $4.5 \mathrm{~cm}$ (1.75 in.) on SR 7 near Harrisonville, Missouri, in August 2013. The three mixes placed in the three test sections included: (1) a control mix containing 30\% RAP using an SBS-modified PG 70-22 binder with no RA; (2) a 40\% RAP mix using the same PG 70-22 binder with RA; and (3) a 25\% RAP and 5\% RAS mix using a neat PG 64-22 with RA. This paper presents data collected during the construction of the test sections, laboratory performance testing results, and early field performance. The research results showed that the recycling agent could be used in the 40\% RAP and 25\% RAP and 5\% RAS mixes to achieve similar construction quality, laboratory performance, and early field performance to the 30\% RAP control mix. As these sections are still in service, it is recommended that they continue to be monitored in order to evaluate their long-term performance. DOI: 10.1061/(ASCE)MT.1943-5533.0001697. (c) 2016 American Society of Civil Engineers.
\end{abstract}

Author keywords: Reclaimed asphalt pavement; Recycled asphalt shingles; Warm mix asphalt; Rejuvenator; Recycling agent.

\section{Introduction}

As material costs-with the asphalt binder being the most expensive component-comprise about $70 \%$ of the total production cost (Copeland 2011), using reclaimed asphalt pavement (RAP) and recycled asphalt shingles (RAS) in asphalt mixtures to replace more valuable virgin binders and aggregates can result in significant cost savings. Use of RAP and RAS in asphalt mixtures also provides

\footnotetext{
${ }^{1}$ Associate Research Professor, National Center for Asphalt Technology, Auburn Univ., Auburn, AL 36830. E-mail: nht0002@auburn.edu

${ }^{2} \mathrm{Ph} . \mathrm{D}$. Candidate, National Center for Asphalt Technology, Auburn Univ., Auburn, AL 36830 (corresponding author). E-mail: zzx0011@ auburn.edu

${ }^{3}$ Assistant Research Engineer, Associate Research Professor, National Center for Asphalt Technology, Auburn Univ., Auburn, AL 36830. E-mail: juliagg@auburn.edu

${ }^{4}$ Assistant Research Engineer, Associate Research Professor, National Center for Asphalt Technology, Auburn Univ., Auburn, AL 36830. E-mail: tayloa3@auburn.edu

${ }^{5}$ Associate Research Professor, National Center for Asphalt Technology, Auburn Univ., Auburn, AL 36830. E-mail: willi59@auburn.edu

${ }^{6}$ Assistant Research Professor, National Center for Asphalt Technology, Auburn Univ., Auburn, AL 36830. E-mail: mmr0001@auburn.edu

${ }^{7}$ Asphalt Performance Manager, Oldcastle Materials Group, Birmingham, AL 35242. E-mail: shane.buchanan@oldcastlematerials.com

Note. This manuscript was submitted on December 17, 2015; approved on May 25, 2016; published online on July 26, 2016. Discussion period open until December 26, 2016; separate discussions must be submitted for individual papers. This paper is part of the Journal of Materials in Civil Engineering, (C) ASCE, ISSN 0899-1561.
}

other environmental benefits, such as conserving energy required to obtain the virgin materials, preserving nonrenewable natural resources, and saving landfill space.

Due to the economic and environmental benefits, there is increasing interest in using more RAP and RAS in asphalt mixtures. Based on the most recent survey conducted by the National Asphalt Pavement Association (NAPA) (Hansen and Copeland 2014), the average percentages of RAP and RAS used in asphalt mixtures by total weight are up to 30 and 5\%, respectively. With these amounts of RAP and RAS, the asphalt mixtures are considered to have high recycled contents as the ratios of recycled binder in RAP and RAS to total binder in these mixes are likely greater than 0.25 (West et al. 2013). As more recycled materials are used, state agencies are increasingly concerned over the durability of asphalt mixtures containing high recycled contents, as these mixes have been found to be prone to more cracking based on laboratory test results.

To address this concern, several national research efforts have been conducted. Analyses (West et al. 2011; Carvalho et al. 2010; Bennert and Maher 2013) were conducted on field performance data from pavement sections in the Specific Pavement Studies 5 (SPS-5) of the Long-Term Pavement Performance (LTPP) program to determine the effect of RAP on long-term field performance. The SPS-5 pavement sections consisted of 5- and 12.7- $\mathrm{cm}$ (2- and 5-in.) overlays. overlays constructed from both virgin and 30\% RAP mixtures on milled and nonmilled surfaces in a variety of climates. Overall, the long-term field performance of asphalt mixtures containing up to $30 \%$ RAP was similar to that of asphalt mixtures with virgin materials (West et al. 2011; Carvalho et al. 2010). A detailed analysis of cracking progression in the LTPP SPS-5 virgin and 30\% 
RAP sections in New Jersey showed that cracks appeared at approximately the same time but progressed faster in the RAP sections.

In addition to examining the LTPP SPS-5 database, another continuing research effort focuses on evaluating the use of emerging technologies to potentially improve the performance of high recycled content mixes. This effort consists of laboratory studies in combination with constructing new pavement sections to evaluate these technologies in various climatic and field conditions that are difficult to simulate using laboratory testing alone (West et al. 2009, 2013; Johnson and Olson 2009; Zhou et al. 2011, 2015; Hajj et al. 2013).

As part of the national effort to improve the long-term field performance of high recycled content mixes, the National Center for Asphalt Technology (NCAT) was tasked under Work Elements V1a and V1b of the Asphalt Research Consortium (ARC) program to coordinate the construction of new pavement validation sites built with high recycled content mixtures utilizing emerging technologies. This paper summarizes research activities and discusses findings from one of the validation sites that was constructed by APAC Missouri, Inc. in August of 2013 on SR 7 approximately $24 \mathrm{~km}$ (15 mi) southeast of Harrisonville, Missouri.

\section{Objectives and Scope}

The overall objective of this validation site was to examine the long-term field performance of high RAP and RAS mixes with a recycling agent (RA), known as Hydrogreen supplied by Green Asphalt Technologies (Pass Christian, Mississippi). The validation site consisted of three test sections, each constructed by placing a dense-graded surface lift at a depth of $4.5 \mathrm{~cm}$ (1.75 in.) The following three test mixes were placed in these sections over 3 days of production:

- The control mix contained 30\% RAP with an SBS-modified PG 70-22.

- The second mix contained $40 \%$ RAP using an SBS-modified PG 70-22 blended with RA.

- The third mix contained 25\% RAP and 5\% RAS using a neat PG 64-22 blended with RA.

In the following sections, some background information is first discussed, followed by information relating to mix design, laboratory performance of the test mixtures, and early field performance of the test sections. Finally, a summary of key findings from this study is provided.

\section{Background}

The aged asphalt binders in RAP and RAS are often stiffer than the corresponding virgin binders; thus, the asphalt mixtures with RAP and RAS are generally stiffer than their comparable virgin mixes. Depending on the contents of RAP and RAS used in the mixes, they can help improve resistance to rutting and moisture damage but can potentially reduce cracking resistance (Cooper et al. 2014, 2015; Kandhal et al. 1995; Hong et al. 2010; Zhou et al. 2011, 2014; West et al. 2011; Tran et al. 2012; Willis 2012; Zhao et al. 2012, 2013, 2015). Therefore, one of the concerns regarding the use of RAP and RAS in asphalt mixtures is the potential for premature cracking of recycled mixes due to the effect of the stiff RAP/RAS binder, especially when higher recycled contents are used.

Recycling agents have been used in asphalt mixtures produced with high recycled contents to mitigate the potential negative effect of the recycled binder on cracking resistance. Several past and ongoing studies have investigated the effect of various RAs on the performance of asphalt mixtures with high RAP and/or RAS contents. Key findings from these studies can be summarized as follows:

- RAs can soften the aged asphalt binders and reduce the stiffness of RAP/RAS mixtures (O'Sullivan 2011; Tran et al. 2012; Mallick et al. 2010; Hajj et al. 2013; Im and Zhou 2014).

- RAs may reduce the resistance to permanent deformation of RAP/RAS mixes (Tran et al. 2012; Zhou et al. 2015).

- RAs can improve the moisture susceptibility of recycled mixtures (Tran et al. 2012; Hajj et al. 2013; Im and Zhou 2014).

- RAs may improve the resistance to cracking of RAP/RAS mixes (Tran et al. 2012; Mallick et al. 2010; Hajj et al. 2013; Im and Zhou 2014; Zhou et al. 2015).

- RAs can also improve the mix resistance to aging (Mogawer et al. 2015).

For this field evaluation site, Hydrogreen (supplied by Green Asphalt Technologies) was used as a recycling agent to improve the field performance of $40 \%$ RAP and $25 \%$ RAP $/ 5 \%$ RAS mixtures. The RA was blended with the corresponding virgin binder used in each mix and was part of the virgin binder in the mix design. This means the mix designs with or without RA are the same, except that in the mix design with RA, the equivalent amount of virgin binder is removed and replaced with the RA determined at the recommended dosage. The following sections of this paper discuss research activities and findings from the field validation study.

\section{Material and Mix Design}

For the validation site near Harrisonville, Missouri, three test sections were constructed using the following three $12.5-\mathrm{mm}$ nominal maximum aggregate size (NMAS) mixtures placed in the surface lift at a depth of $4.5 \mathrm{~cm}$ (1.75 in.):

- The control mix contained 30\% RAP and an SBS-modified PG 70-22 (PG 64-22 Grade H) base binder with no RA (referred to as $30 \%$ RAP mix).

- The second mix contained 40\% RAP and an SBS-modified PG 70-22 (PG 64-22 Grade H) base binder blended with $0.75 \%$ RA by weight of RAP (referred to as $40 \%$ RAP mix).

- The third mix contained 25\% RAP and 5\% RAS and a neat PG 64-22 base binder blended with $1.33 \%$ RA by weight of RAS (referred to as $25 \%$ RAP/5\% RAS mix).

The three mix designs were approved by the Missouri Department of Transportation (MoDOT) before construction. Each fine-graded 12.5-mm NMAS Superpave mix was designed with a compactive effort of 80 gyrations. The RAP was not crushed prior to adding to the plant, but an in-line RAP crusher was used to crush the oversized material to $-1.27 \mathrm{~cm}(-1 / 2$ in.) The RAS used for the $25 \%$ RAP/5\% RAS mix was postconsumer RAS, which was ground off-site to $-1 \mathrm{~cm}(-3 / 8$ in.) in Stanley, Kansas, and then delivered to the plant. The RAP and RAS were added in separate cold-feed bins. The aggregate used for the design and production was limestone and mine chat.

The same virgin materials were used for all three mixes. The proportions of the virgin material were changed, but the volumetrics and gradations of the overall designs were similar. An SBSmodified PG 70-22 (PG 64-22 Grade H) liquid asphalt binder supplied by Conoco Phillips in Kansas City, Missouri, was used as the virgin binder for the $30 \%$ RAP and $40 \%$ RAP mixes. A virgin PG 64-22 binder from the same supplier was used for the $25 \%$ RAP/5\% RAS mix. The liquid antistrip Morelife T280 [Ingevity (MeadWestvco), North Charleston, South Carolina] was added at a rate of $0.8 \%$ by weight of virgin binder for all three mixes. The rejuvenator was preblended with the virgin binder at the 
Table 1. Design Gradation, Asphalt Content, and Volumetrics for Mix Design

\begin{tabular}{|c|c|c|c|c|}
\hline $\begin{array}{l}\text { Sieve size } \\
\text { mm (in.) }\end{array}$ & $30 \%$ RAP & $40 \%$ RAP & $\begin{array}{c}25 \% \text { RAP } / 5 \% \\
\text { RAS }\end{array}$ & $\begin{array}{l}\text { Control } \\
\text { points }\end{array}$ \\
\hline $19.0\left(3 / 4^{\prime \prime}\right)$ & 100 & 100 & 100 & 100 \\
\hline $12.5\left(1 / 2^{\prime \prime}\right)$ & 94 & 96 & 95 & $90-100$ \\
\hline $9.5\left(3 / 8^{\prime \prime}\right)$ & 88 & 90 & 89 & $90 \max$ \\
\hline $4.75(\# 4)$ & 66 & 72 & 66 & - \\
\hline $2.36(\# 8)$ & 44 & 50 & 43 & $28-58$ \\
\hline $1.18(\# 16)$ & 31 & 36 & 31 & - \\
\hline $0.6(\# 30)$ & 20 & 24 & 21 & - \\
\hline $0.3(\# 50)$ & 13 & 16 & 15 & - \\
\hline $0.15(\# 100)$ & 8 & 9 & 10 & - \\
\hline $0.075(\# 200)$ & 6.2 & 7.1 & 7.5 & $2-10$ \\
\hline Total AC (\%) & 5.2 & 5.2 & 5.3 & - \\
\hline Virgin $\mathrm{AC}$ added $^{\mathrm{a}}$ & $4.3(0.83)$ & $3.6(0.69)^{\mathrm{b}}$ & $3.4(0.64)^{\mathrm{b}}$ & - \\
\hline $\mathrm{AC}$ from $\mathrm{RAP}^{\mathrm{a}}$ & $0.9(0.17)$ & $1.6(0.31)$ & $0.9(0.17)$ & - \\
\hline $\mathrm{AC}$ from $\mathrm{RAS}^{\mathrm{a}}$ & 0 & 0 & $1.0(0.19)$ & - \\
\hline Air voids (\%) & 4.0 & 4.0 & 4.0 & - \\
\hline$G_{m b} @ N_{\mathrm{des}}$ & 2.319 & 2.335 & 2.325 & - \\
\hline$G_{m m}$ & 2.416 & 2.433 & 2.422 & - \\
\hline VMA (\%) & 15.1 & 14.8 & 15.2 & $>14.0$ \\
\hline VFA $(\%)$ & 73.0 & 72.8 & 73.5 & $65-75$ \\
\hline Vbe $(\%)$ & 11.1 & 10.8 & 11.2 & - \\
\hline$G_{s b}$ & 2.590 & 2.599 & 2.595 & - \\
\hline$G_{s e}$ & 2.607 & 2.628 & 2.619 & - \\
\hline$P_{b a}(\%)$ & 0.26 & 0.44 & 0.36 & - \\
\hline$P_{b e}(\%)$ & 4.95 & 4.78 & 4.95 & - \\
\hline $\mathrm{D} / \mathrm{A}$ ratio & 1.3 & 1.5 & 1.5 & $0.8-1.6$ \\
\hline
\end{tabular}

${ }^{\mathrm{a} B i n d e r}$ content and (ratio of virgin AC, RAP AC, or RAS AC to total AC).

${ }^{\mathrm{b}}$ Virgin binder was preblended with the rejuvenator.

recommended dosage before mixing with aggregates. The base binder used in the 30\% RAP mix contained no RA. The approved job mix formulas (JMFs) and control points are shown in Table 1.

\section{Production and Construction}

The plant used for this field evaluation was located in Harrisonville, Missouri, approximately $23 \mathrm{mi}$ north of the paving site. This Terex CMI counter-flow drum plant incorporated a Maxam AquaBlack foaming system to use as a compaction aid for this project. This plant had two silos, each with a 200-t capacity. Recycled No. 4 fuel was used to power this plant. The foaming allows for maximum coating of the aggregate as well as improved compactability at lower temperatures. The water was injected at a rate of $2 \%$ by weight of base binder for all three mixes.

A Caterpillar AP-1055E paver was used to pave these mixes. The asphalt mixtures were delivered using a variety of truck types including long dump beds, triaxle dump beds, and quad-axle dump beds. All trucks were covered, and a cycle of 15 trucks was used for each mix. A Weiler E2850 material transfer vehicle (MTV) was used to transfer the mixes to the paver. The temperature of the mix was measured every 5-20 min in the auger and behind the paver with a handheld temperature gun. Table 2 shows the temperatures of the mix in the behind the screed. The three mixes were paved at similar temperatures with the $40 \%$ RAP mix having a higher standard deviation than the others. However, it is unclear whether the variation was attributable to the higher RAP content.

All three mixes were compacted using the same three rollers. The breakdown roller was a Caterpillar C864 steel wheel roller. The rolling pattern for all three mixes was two passes on the joint, two passes on the edge of shoulder, and then forward in the center and back on the joint. A pass here is defined as both wheels of the
Table 2. Temperatures of Mix behind the Screed

\begin{tabular}{lrrr}
\hline Temperature & $30 \%$ & $40 \%$ & $25 \% \mathrm{RAP} / 5 \%$ \\
$\left({ }^{\circ} \mathrm{F}\right)$ & $\mathrm{RAP}$ & $\mathrm{RAP}$ & $\mathrm{RAS}$ \\
\hline Average & 267.5 & 262.1 & 268.8 \\
SD & 7.3 & 12.2 & 5.5 \\
Maximum & 285.0 & 286.5 & 280.5 \\
Minimum & 256.0 & 221.5 & 260.0 \\
\hline
\end{tabular}

Table 3. In-Place Density from Cores

\begin{tabular}{lcccc}
\hline & & $30 \%$ & $40 \%$ & $25 \%$ RAP $/ 5 \%$ \\
Test & Statistic & RAP & RAP & RAS \\
\hline In-place & Average & 92.9 & 92.3 & 94.0 \\
density (\%) & SD & 1.08 & 2.23 & 0.71 \\
\hline
\end{tabular}

machine rolling over a specific point on the mat. The intermediate roller was an Ingersoll Rand PT-240R rubber-tire roller. The rolling pattern for the intermediate roller was also the same for all mixes. The rolling pattern was two passes on each side in static mode. The finishing roller used on this project was a Caterpillar CB 54 steel-wheel roller. This roller was operated in the static mode for two passes on each side.

After construction, six 150-mm (6-in.) cores were obtained from each mix section. These cores were taken back to the lab, and the density of the surface layer was determined for the cores from each mix after trimming from the underlying layers. Average core density results are shown in Table 3 . It was observed that the average in-place density for the three mixes was similar and higher than the in-place density requirement of $92 \% G_{m m}$. Therefore, these mixes had similar compactability under the same compaction effort.

\section{Laboratory Performance Testing}

\section{Binder Grading}

Table 4 shows the performance grades (PG) of six binders. The three tank binders were sampled at the plant during production. The tank binder used to produce the $30 \%$ RAP mix was not blended with RA, but the tank binders used for the $40 \%$ RAP and $25 \%$ RAP/ 5\% RAS mixes were blended with 0.75 and $1.33 \%$ RA by weight of RAP and RAS materials, respectively. The dosage of RA was higher in the $25 \%$ RAP/5\% RAS mix because of the stiffer postconsumer RAS binder used in this mix. The recovered binders shown in Table 4 were extracted from plant mixes in accordance with Method A of AASHTO T164 (AASHTO 2014) and then recovered in accordance with ASTM D5404/D5404M (ASTM 2012). After extraction and recovery, the recovered binder from each mix was graded according to AASHTO M320 and AASHTO R29 (AASHTO 2010b, 2011b) to determine continuous and PG grades.

Table 4. Asphalt Testing Results

\begin{tabular}{lcccc}
\hline \multirow{2}{*}{ Material } & Test & $30 \%$ & $40 \%$ & 25\% RAP/ \\
\hline Tank & RAP mix & RAP mix & 5\% RAS mix \\
binder & PG grade & $71.7-23.7$ & $64.5-27.6$ & $58.2-31.3$ \\
& Rotational viscosity & 0.615 & 0.400 & $58-28$ \\
& @ $135^{\circ} \mathrm{C}, \mathrm{PaS}$ & & & \\
Recovered & True grade & $82.2-27.7$ & $86.9-25.1$ & $88.6-26.9$ \\
binder & PG grade & $82-22$ & $82-22$ & $88-22$ \\
\hline
\end{tabular}


As required by MoDOT for this field trial, the performance grades of the binders extracted from the $40 \%$ RAP and $25 \%$ $\mathrm{RAP} / 5 \%$ RAS mixes must be equal or better than that of the binder extracted from the control $30 \%$ RAP mix. To meet this requirement, the base binders used to produce the $40 \%$ RAP and 25\% RAP / 5\% RAS mixes were blended with $0.75 \%$ and $1.33 \%$ RA by weight of RAP and RAS and graded as PG 64-22 and PG 58-28, respectively. As shown in Table 4, with the recommended dosages, the binders recovered from the corresponding plant mixes met the MoDOT requirement - to be graded as PG $82-22$ or better. It was also observed that the binder with RA for $25 \%$ RAP/5\% RAS mixes showed the lowest rotational viscosity at $135^{\circ} \mathrm{C}$, followed by that for $40 \%$ RAP mix and by that for $30 \%$ RAP.

\section{Mixture Performance Testing}

To evaluate the effect of the RA on performance of mixtures with high RAP and RAS, the following laboratory tests were conducted in this study: (1) Hamburg wheel-track (Hamburg) testing to determine both the rutting and stripping susceptibility; (2) tensile strength ratio (TSR) test to evaluate moisture susceptibility; (3) dynamic modulus $\left(E^{*}\right)$ test to compare the linear viscoelastic characteristics; (4) overlay test (OT) to determine the resistance to cracking at intermediate temperatures; and (5) indirect tensile testing (IDT) to investigate the resistance to cracking at low temperatures.

As for the aforementioned volumetric samples, specimens for performance tests were also plant-mixed/lab-compacted (PMLC) on-site in the mobile lab. During the specimen preparation, mix was split out at trial masses for each specimen type and compacted to the required height once the compaction temperature $\left[130^{\circ} \mathrm{C}\right.$ $\left.\left(265^{\circ} \mathrm{F}\right)\right]$ was reached. These trial specimens were then bulked according to AASHTO T166 to determine $G_{m b}$ and air voids. These data were then used to determine the required mass for each specimen type to reach the required air void level for the performance tests. In addition, field cores were also extracted to test for IDT low temperature cracking.

The following subsections briefly describe each laboratory testing procedure and discuss testing results to characterize the performance of the mixes evaluated in this field study.

\section{Hamburg Wheel-Tracking Test}

Hamburg wheel-track testing was performed to determine both the rutting and stripping susceptibility of the mixtures sampled in this project. Testing was performed in accordance with AASHTO T324-11 (AASHTO 2011a). Three replicates were tested per mix. The specimens were originally compacted using an SGC to a diameter of $150 \mathrm{~mm}$ and a height of $95 \mathrm{~mm}$. These specimens were then trimmed so that two specimens, with a height between 38 and $50 \mathrm{~mm}$, were cut from the top and bottom of each gyratory-compacted specimen. The air voids of these cut specimens were $7.0 \pm 1.0 \%$.

The specimens were tested under a $71.1 \pm 0.5 \mathrm{~kg}(158 \pm 1 \mathrm{lb})$ wheel load for 10,000 cycles (20,000 passes) while submerged in a water bath maintained at a temperature of $50^{\circ} \mathrm{C}$. While being tested, rut depths were measured by an linear variable differential transformer (LVDT), which recorded the relative vertical position of the load wheel after each load cycle. After testing, these data were used to determine the point at which stripping occurred in the mixture under loading as well as the relative rutting susceptibility of those mixtures.

Comparing the stripping inflection points and total rutting of the different mixtures gives a measure of the relative moisture and deformation susceptibility of the mixtures. A stripping inflection point of greater than 10,000 passes has been considered to be an
Table 5. Texas Department of Transportation Requirements for Hamburg Testing

\begin{tabular}{lc}
\hline $\begin{array}{l}\text { High-temperature } \\
\text { binder grade }\end{array}$ & $\begin{array}{c}\text { Minimum passes to } 12.7 \mathrm{~mm} \\
(0.5 \text { in. }) \text { rut depth }\end{array}$ \\
\hline PG 64 or lower & 10,000 \\
PG 70 & 15,000 \\
PG 76 or higher & 20,000 \\
\hline
\end{tabular}

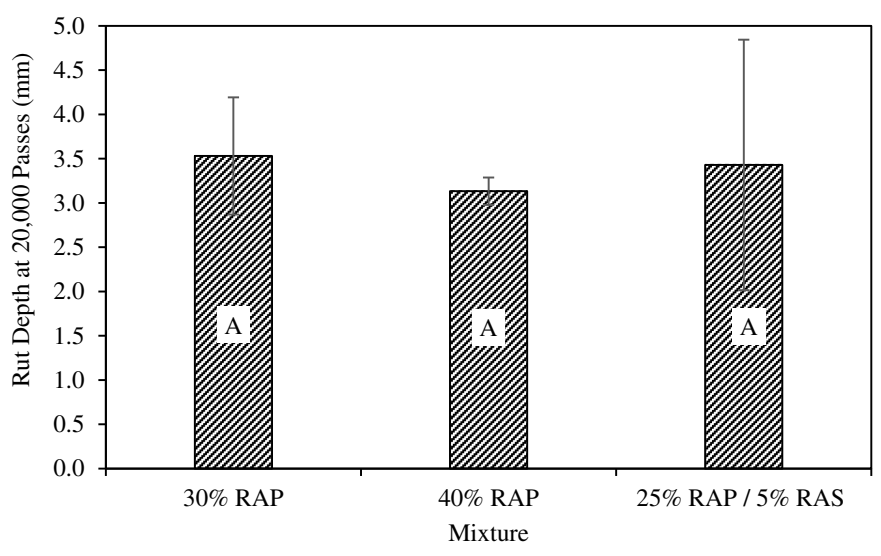

Fig. 1. Hamburg test results

indicator of a moisture-resistant mixture. The Texas Department of Transportation (TxDOT) uses the criteria in Table 5 to evaluate the rutting resistance of their asphalt mixtures.

Fig. 1 shows the average rut depth of triplicate specimens for the three mixes at 20,000 wheel passes. All three mixtures passed TxDOT's criteria of $12.5 \mathrm{~mm}$ at 20,000 wheel passes. The $40 \%$ RAP and 30\% RAP mixes exhibited the lowest and highest rut depths, respectively.

A one-way ANOVA statistical test with Tukey-Kramer statistical groupings was conducted on the rutting results at a significance level $(\alpha)$ of 0.05 . The results of the statistical test suggested that the rutting resistance of these mixes was not significantly different.

Besides the rutting depth, the striping inflection point (SIP) obtained from the Hamburg test was also used to evaluate the moisture susceptibility of these mixes. No stripping was observed for these mixes in the Hamburg test, indicating that the resistance to moisture damage of these mixes was acceptable.

\section{Tensile Strength Ratio Test}

Tensile strength ratio moisture susceptibility testing was performed for this project in accordance with AASHTO T283 (AASHTO 2012b). This methodology uses 95-mm samples compacted in an superpave gyratory compactor (SGC). The target air void level for these samples was $7.0 \pm 0.5 \%$.

A set of three specimens was vacuum saturated so that $70-80 \%$ of the internal voids were saturated with water. The samples were then placed in a freezer for a minimum of $16 \mathrm{~h}$ prior to being placed in a warm water bath $\left(60^{\circ} \mathrm{C}\right)$ for $24 \mathrm{~h}$. This process constitutes one freeze-thaw cycle. These conditioned specimens, along with a group of three unconditioned specimens that had not been saturated, were then tested for indirect tensile strength (ITS) using a Marshall press apparatus. In this test, all samples are placed in a $25^{\circ} \mathrm{C}$ water bath for $2 \mathrm{~h}$ to equilibrate their temperature. The ratio of the indirect tensile strengths of the conditioned and unconditioned samples is recorded as the tensile-strength ratio. 


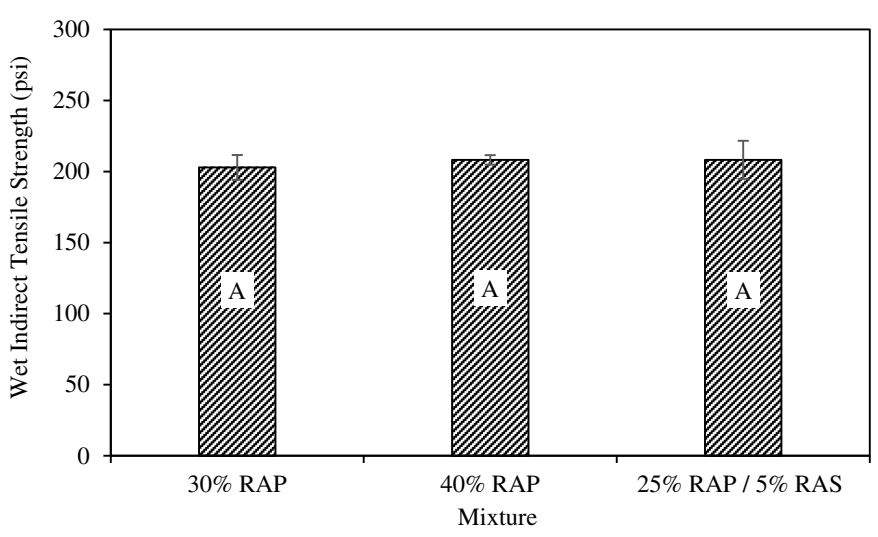

Fig. 2. Comparison of wet indirect tensile strength results

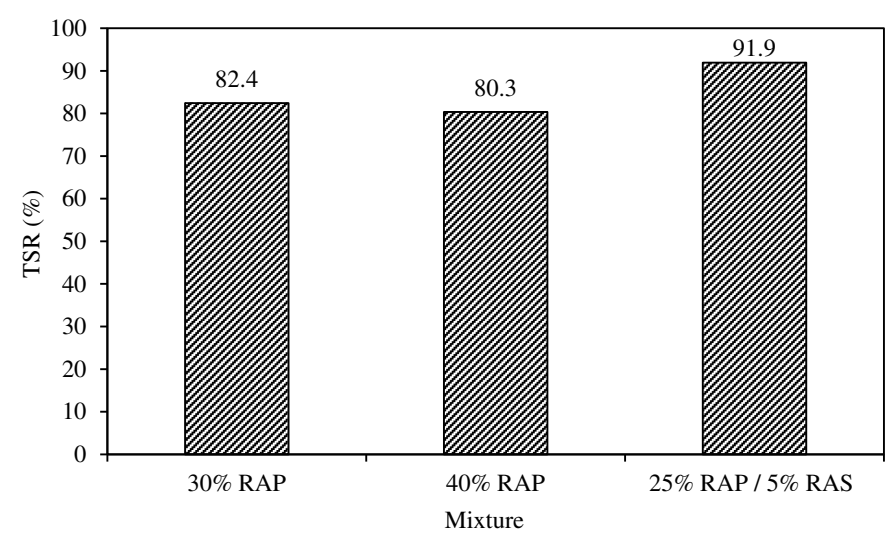

Fig. 3. Comparison of TSR results

In accordance with AASHTO R35 (AASHTO 2012a), the minimum TSR criteria is 0.8 for moisture-resistant mixes, indicating less than a $20 \%$ reduction in splitting tensile strength given conditions conducive to moisture-induced damage.

Fig. 2 compares the average wet indirect tensile strengths of triplicate specimens. A one-way ANOVA $(\alpha=0.05)$ with TukeyKramer statistical groupings showed that the difference between the wet IDT strengths of the three mixes was not statistically significant. The TSR values for all the mixtures tested in this study (Fig. 3) were equal or greater than the commonly accepted failure threshold of 0.8. Overall, the use of RA and foaming technology in producing these high recycled content mixtures did not negatively affect their resistance to moisture damage.

\section{Dynamic Modulus Test}

The samples for this testing were prepared in accordance with AASHTO PP60-09 (AASHTO 2009). The samples were compacted to a height of $175 \mathrm{~mm}$ and a diameter of $150 \mathrm{~mm}$, then cut and cored to a height of $150 \mathrm{~mm}$ and a diameter of $100 \mathrm{~mm}$. The target air void level for these specimens was $7.0 \pm$ $0.5 \%$ after trimming. Three samples were prepared for testing from each mix. Dynamic modulus testing was performed in accordance with AASHTO TP79-12 (AASHTO 2012c) in an IPC global asphalt mixture performance tester (AMPT). This testing was performed unconfined and test data were screened for data quality in accordance with the limits set in AASHTO TP 79-12 (AASHTO 2012c). The temperatures and frequencies used for testing these

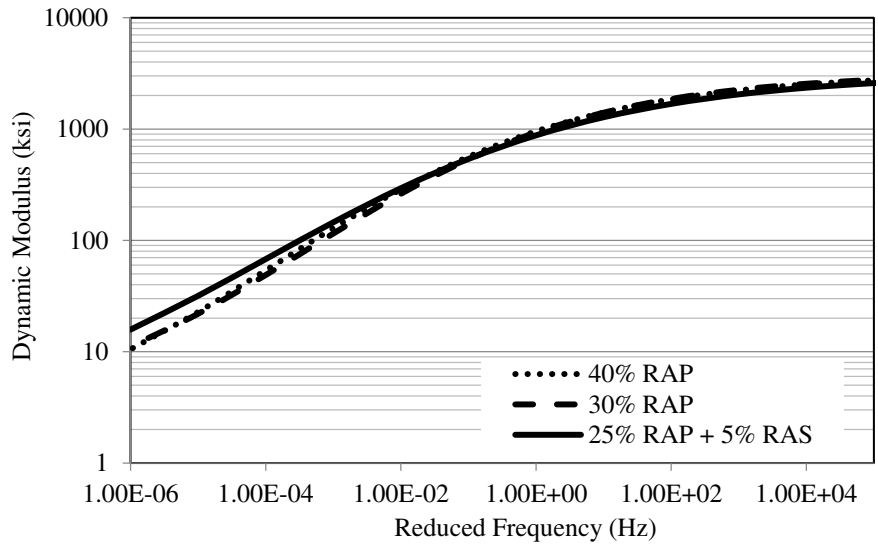

Fig. 4. Comparison of $E$ test results

mixes are those recommended by AASHTO PP61-10 (AASHTO 2010a). The collected data were used to generate a master curve for each mix. The master curve uses the principle of time-temperature superposition to shift data at multiple temperatures and frequencies to a reference temperature so that the stiffness data can be viewed without temperature as a variable. This method of analysis allows for visual relative comparisons to be made between multiple mixes.

Fig. 4 compares the $E^{*}$ master curves at the reference temperature of $20^{\circ} \mathrm{C}$ for the three mixes. The $E^{*}$ master curves for the $30 \%$ RAP and $40 \%$ RAP mixes overlapped each other, indicating the softening effect of RA on stiffness of the $40 \%$ RAP mixture. The $25 \%$ RAP/5\% RAS mixture exhibited slightly lower $E^{*}$ at higher reduced frequencies (lower temperatures) but slightly higher $E^{*}$ at lower reduced frequencies (higher temperatures) than the other mixes.

\section{Overlay Test}

The Texas overlay test is designed to simulate accelerated reflective cracking in asphalt concrete overlays. The TxDOT 248-F specification is the current testing methodology used for conducting the overlay test. In this study, the overlay test was conducted using a fixture and software within the IPC Global AMPT. For this test, SGC specimens were compacted to a target height of $125 \mathrm{~mm}$. Upon achieving the desired height, two specimens per pill were trimmed to the following dimensions: $150 \mathrm{~mm}$ (6 in.) long, by $75 \mathrm{~mm}$ ( 3 in.) wide by $38 \mathrm{~mm}$ (1.5 in.) tall. Target air voids for the cut specimens was $7.0 \pm 1.0 \%$. The specimens were glued to two aluminum plates using a two-part epoxy. A minimum of three replicates was desired for each mixture in the testing plan.

In this procedure, the samples are tested at $25^{\circ} \mathrm{C}$ in the controlled displacement mode. Loading occurs when a movable steel plate attached to the asphalt specimen slides away from the other plate. Loading occurs at a rate of one cycle every $10 \mathrm{~s}$ with a sawtooth waveform, and the maximum displacement per cycle is $0.63 \mathrm{~mm}$ (0.025 in.). The maximum load the specimen resists in controlled displacement mode is recorded for each cycle. The test continues until sample failure, which is defined as a $93 \%$ reduction in load magnitude from the first cycle (Tex 248-F).

The number of cycles to failure was determined for each mix. A mix with a higher number of cycles to failure may have better resistance to reflective cracking. Table 6 summarizes the test results, and Fig. 5 compares the average number of cycles to failure determined through the overlay testing. The $30 \%$ RAP mix had a higher average number of cycles to failure than the other mixes, 
Table 6. Summary of Overlay Test Results

\begin{tabular}{lcccccc}
\hline & & & \multicolumn{3}{c}{$\begin{array}{c}93 \% \text { load reduction- } \\
\text { cycles to failure }\end{array}$} \\
\cline { 5 - 7 } Mix identifier & $\begin{array}{c}\text { Average air } \\
\text { voids (\%) }\end{array}$ & $\begin{array}{c}\text { Number } \\
\text { of tests }\end{array}$ & Average & SD & CV (\%) \\
\hline $30 \%$ RAP & 6.9 & 3 & 38 & 29.4 & 76.6 \\
40\% RAP & 6.9 & 4 & 17 & 6.2 & 37.2 \\
25\% RAP/5\% RAS & 7.1 & 4 & 16 & 11.2 & 69.1 \\
\hline
\end{tabular}

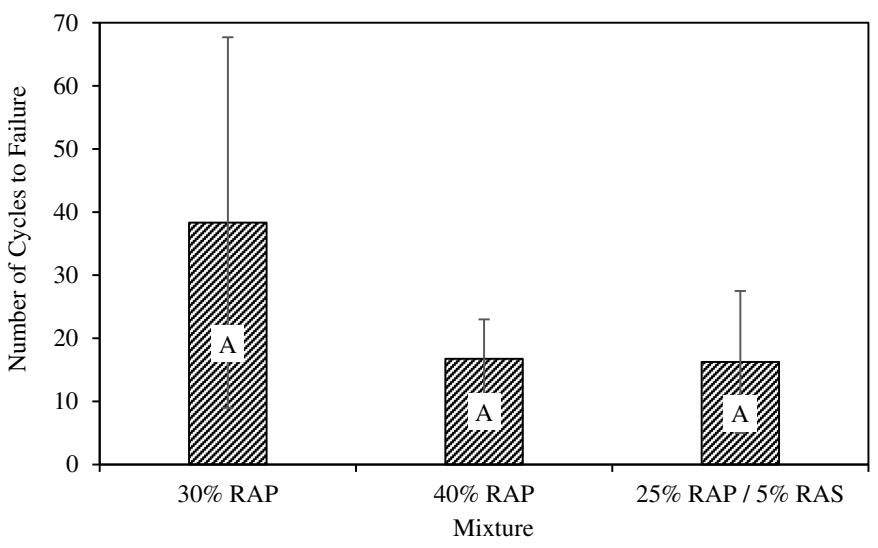

Fig. 5. Comparison of overlay tester results

which showed similar average cycles to failure. However, based on a statistical comparison [one-way ANOVA $(\alpha=0.05)$ with Tukey-Kramer statistical groupings], the difference in the number of cycles to failure between the three mixtures was not significant when considering the OT variability, making it difficult to distinguish the effect of the RA based on the OT results.

\section{Low Temperature Indirect Tensile Test}

The low-temperature cracking susceptibility of the mixes used in this study was evaluated using the AASHTO T322-07 (AASHTO 2007) procedure. The testing was conducted using an indirect tensile testing system with an MTS load frame and an environmental chamber capable of maintaining the required temperatures. Creep compliances at $0,-10$, and $-20^{\circ} \mathrm{C}$ and a tensile strength at $-10^{\circ} \mathrm{C}$ were measured in accordance with AASHTO T322-07 (AASHTO 2007). These temperatures are specified as a function of the lowtemperature PG grade of the binder in AASHTO T322-07 (AASHTO 2007). The indirect tensile test was conducted on both the PMLC specimens and cores extracted from the field test sections. PMLC specimens were compacted to $125 \mathrm{~mm}$ tall and

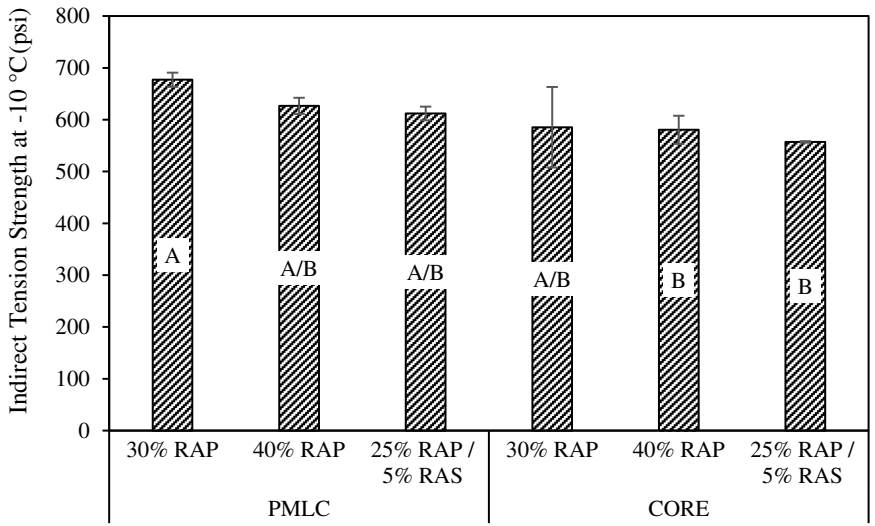

Fig. 6. Indirect tension strength at $-10^{\circ} \mathrm{C}$

$150 \mathrm{~mm}$ in diameter prior to being trimmed. Four cut specimens were prepared for each mixture. Specimens used for the creep and strength tests were $150 \mathrm{~mm}$ in diameter and trimmed to a thickness of $38-50 \mathrm{~mm}$. Trimmed specimens were prepared to $7.0 \pm$ $0.5 \%$ air voids.

Table 7 summarizes the low-temperature cracking results. Fig. 6 shows the indirect tension strength at $-10^{\circ} \mathrm{C}$. As shown Fig. 6 , the $30 \%$ RAP mix had the highest IDT strength at $-10^{\circ} \mathrm{C}$, followed by the $40 \%$ RAP and $25 \%$ RAP/5\% RAS mixes for both the PMLC specimens and field cores. A one-way ANOVA $(\alpha=0.05)$ with Tukey-Kramer statistical groupings was performed to verify the statistical differences in indirect tension strength at $-10^{\circ} \mathrm{C}$ for the three mixes. The statistical results are presented in Fig. 6 with A and $\mathrm{B}$ representing groupings with statistically different IDT strength results. The PMLC set of specimens for the 30\% RAP mix had statistically higher IDT strength results than the other sets of specimens, which had statistically similar IDT strength results.

\section{Early Field Performance}

A field performance evaluation of the validation site near Harrisonville, Missouri, was conducted on June 20, 2014 after approximately 10 months of traffic was applied to its three test sections. The following subsections summarize the field performance results.

\section{Rutting}

The rut depths were measured at the beginning of each $200-\mathrm{ft}$ section with a straight edge and a wedge. After 10 months, all three test sections had performed well in terms of rutting. None of the

Table 7. Summary of Low Temperature Cracking Results

\begin{tabular}{|c|c|c|c|c|c|c|}
\hline \multirow[b]{2}{*}{ Mix identifier } & \multirow{2}{*}{$\begin{array}{l}\text { Average air } \\
\text { voids }(\%)\end{array}$} & \multirow{2}{*}{$\begin{array}{c}\text { Number } \\
\text { of tests }\end{array}$} & \multicolumn{3}{|c|}{ IDT values at $-10^{\circ} \mathrm{C}$} & \multirow{2}{*}{$\begin{array}{c}\text { Critical low } \\
\text { temperature }\left({ }^{\circ} \mathrm{C}\right)\end{array}$} \\
\hline & & & Average (psi) & SD & $\mathrm{CV}(\%)$ & \\
\hline $30 \%$ RAP PMLC & 7.0 & 3 & 677 & 13.6 & 2.0 & -17 \\
\hline 40\% RAP PMLC & 6.8 & 3 & 627 & 15.7 & 2.5 & -14 \\
\hline $25 \%$ RAP $/ 5 \%$ RAS PMLC & 6.9 & 3 & 612 & 13.2 & 2.2 & -18 \\
\hline $30 \%$ RAP core & 7.1 & 3 & 585 & 77.8 & 13.3 & -13 \\
\hline $40 \%$ RAP core & 6.6 & 3 & 581 & 27.2 & 4.7 & -16 \\
\hline $25 \%$ RAP/5\% RAS core & 6.6 & 3 & 557 & 1.5 & 0.3 & -13 \\
\hline
\end{tabular}

Note: $\mathrm{CV}=$ coefficient of variation; $\mathrm{SD}=$ standard deviation. 
Table 8. Total Cracking Observed in Harrisonville, MO after 10 Months

\begin{tabular}{lccc}
\hline & & \multicolumn{2}{c}{ Transverse cracking } \\
\cline { 3 - 4 } Mix section & Severity & $\begin{array}{c}\text { Number } \\
\text { of cracks }\end{array}$ & $\begin{array}{c}\text { Total } \\
\text { length [m (ft)] }\end{array}$ \\
\hline $30 \%$ RAP & Low & 3 & $9.1(30)$ \\
& Moderate & 0 & 0.0 \\
$40 \%$ RAP & High & 0 & 0.0 \\
& Low & 3 & $11.0(36)$ \\
$25 \%$ RAP/5\% RAS & Moderate & 0 & 0.0 \\
& High & 0 & 0.0 \\
& Low & 6 & $22.0(72)$ \\
& Moderate & 0 & 0.0 \\
& High & 0 & 0.0 \\
\hline
\end{tabular}

three data sections from any mix exhibited any measurable rutting after 10 months.

\section{Cracking}

The entirety of each 200-ft section was carefully inspected for visual signs of cracking and rated based on the LTPP Distress Identification Manual (Miller and Bellinger 2003). All of the three test sections exhibited some low-severity ( $<6 \mathrm{~mm}$ wide) transverse cracking. Table 8 shows the total cracking observed for each test section. As shown in Table 8, the $30 \%$ RAP mix had a total of $30 \mathrm{ft}$ of cracking, and the $40 \%$ RAP mix had a total of $36 \mathrm{ft}$ of cracking, compared to a total of $72 \mathrm{ft}$ of cracking for the $25 \%$ RAP and $5 \%$ RAS mix. The majority of transverse cracking was deemed to be reflective cracking, since the cracks propagated across both lanes and the shoulder.

\section{Conclusions and Recommendations}

To mitigate the potential negative effect of the RAP/RAS binder on the durability of asphalt mixtures with high recycled contents, a national research effort has been spent on evaluating the use of emerging technologies to improve the durability of these mixes. As part of this effort, this field study was conducted to evaluate the long-term field performance of high RAP and RAS mixes with a recycling agent (RA) known as Hydrogreen, supplied by Green Asphalt Technologies. The field study consisted of three test sections on SR 7 (approximately $24 \mathrm{~km}$ (15 mi.) southeast of Harrisonville, Missouri), each constructed by placing a dense-graded surface lift at a depth of $4.5 \mathrm{~cm}$ (1.75 in.) in August 2013. The three mixes placed in the three test sections included

- 30\% RAP mix (control) produced with an SBS-modified PG 70-22 binder with no RA.

- $40 \%$ RAP mix produced with the same PG 70-22 binder blended with $0.75 \%$ RA by weight of RAP.

- $25 \%$ RAP and 5\% RAS mix produced with a neat PG 64-22 binder blended with $1.33 \%$ RA by weight of RAP and RAS.

This paper describes the construction activities, presents the laboratory test results of asphalt mixtures sampled during production, and discusses the early field performance of the test sections. Based on the results presented in this paper, the following key findings are offered:

- While the three mixes were designed with different proportions of virgin and recycled materials, their gradations and volumetric properties were very similar. The dosages of RA were determined for the $40 \%$ RAP and $25 \%$ RAP/5\% RAS mixes to achieve the same level of field performance as the control mix.
The RA was then blended with and replaced the equivalent amounts of the corresponding virgin binders used in the $40 \%$ RAP and $25 \%$ RAP $/ 5 \%$ RAS mixes. The binder contents of these two mixes were similar with and without RA. MoDOT approved all of the mix designs before construction.

- The three mixes were compacted using the same rolling patterns with breakdown, intermediate, and finishing rollers. The three test sections met the MoDOT in-place density requirement of 92\% measured by field cores.

- With the recommended dosages of RA, the binders recovered from the corresponding plant mixes met the MoDOT requirement - the performance grades of the binders extracted from the $40 \%$ RAP and $25 \%$ RAP/5\% RAS mixes were PG 82-22 and PG 88-22, respectively, which were equal to or better than that extracted from the control 30\% RAP mix (PG 82-22).

- The use of RA in the $40 \%$ RAP and $25 \%$ RAP/5\% RAS mixes yielded statistically similar resistance to intermediatetemperatue and low-temperature cracking to that of the $30 \%$ RAP mix in the laboratory without negatively affecting the mix resistance to rutting and moisture damage. The mix resistance to rutting and moisture damage was determined based on the Hamburg wheel-track and tensile strength ratio tests, while the mix resistance to intermediate-temperature cracking and lowtemperature cracking was evaluated based on the overlay test and the low-temperature indirect tensile test, respectively.

- Based on the dynamic modulus test results, the stiffness of the $40 \%$ RAP mix was very close to that of the $30 \%$ RAP mix, suggesting that the RA lowered the stiffness of the $40 \%$ RAP mixture. The $25 \%$ RAP/5\% RAS mixture was stiffer at high temperatures and slightly softer at low temperatures than the other mixes, but these differences were not statistically significant.

- Based on the field survey of the three test sections at 10 months after construction, none exhibited any measurable rutting. However, low-severity reflective cracking was observed in all sections, with the $25 \%$ RAP/5\% RAS mix section having more cracks than the other two sections.

In summary, a recycling agent can be used in asphalt mixtures with higher recycled contents to achieve similar in-place density and laboratory and early field performance as those with lower recycled contents. As these sections are still in service, it is recommended that they continue to be monitored in order to evaluate their long-term performance.

\section{Acknowledgments}

The authors would like to thank the Federal Highway Administration, Asphalt Research Consortium, Oldcastle Material Group, APAC Missouri, and Green Asphalt Technologies for their support and assistance in this research project.

\section{References}

AASHTO. (2007). "Standard method of test for determining the creep compliance and strength of hot-mix asphalt (HMA) using the indirect tensile test device." AASHTO T322, Washington, DC.

AASHTO. (2009). "Standard practice for preparation of cylindrical performance test specimens using the superpave gyratory compactor (SGC)." AASHTO PP60, Washington, DC.

AASHTO. (2010a). "Standard practice for developing dynamic modulus master curves for hot mix asphalt (HMA) using the asphalt mixture performance tester (AMPT)." AASHTO PP61, Washington, DC.

AASHTO. (2010b). "Standard specification for performance-graded asphalt binder." AASHTO M320, Washington, DC. 
AASHTO. (2011b). "Practice for grading or verifying the performance grade (PG) of an asphalt binder." AASHTO R29, Washington, DC.

AASHTO. (2011a). "Standard method of test for hamburg wheel-track testing of compacted hot-mix asphalt (HMA)." AASHTO T324, Washington, DC

AASHTO. (2012c). "Standard method of test for determining the dynamic modulus and flow number for asphalt mixtures using the asphalt mixture performance tester (AMPT)." AASHTO TP79, Washington, DC.

AASHTO. (2012b). "Standard method of test for resistance of compacted asphalt mixtures to moisture-induced damage." AASHTO T283, Washington, DC.

AASHTO. (2012a). "Standard practice for superpave volumetric design for asphalt mixtures." AASHTO R35, Washington, DC.

AASHTO. (2014). "Standard method of test for quantitative extraction of asphalt binder from hot mix asphalt (HMA)." AASHTO T164, Washington, DC.

ASTM. (2012). "Standard practice for recovery of asphalt from solution using the rotary evaporator." ASTM D5404/D5404M, West Conshohocken, PA.

Bennert, T., and Maher, A. (2013). "Forensic study on the cracking distress of New Jersey's LTPP SPS-5 sections-30\% RAP versus virgin hot mix asphalt (HMA)." Transp. Res. Rec., 2371, 74-86.

Carvalho, R., Shirazi, H., Ayres, M., and Selezneva, O. (2010). "Performance of recycled hot-mix asphalt overlays in rehabilitation of flexible pavements." Transp. Res. Rec., 2155, 55-62.

Cooper, S., Mohammad, L., and Elseifi, M. (2014). "Laboratory performance of asphalt mixtures containing recycled asphalt shingles." Transp. Res. Rec., 2445, 94-102.

Cooper, S., Mohammad, L., Elseifi, M., and Medeiros, M. (2015). "Effect of recycling agents on the laboratory performance of asphalt mixtures containing recycled asphalt shingles." Transp. Res. Rec., 2506, 54-61.

Copeland, A. (2011). "Reclaimed asphalt pavement in asphalt mixtures: State of the practice." Rep. No. FHWA-HRT-11-021, FHWA, Washington, DC.

Hajj, E., Souliman, M., Alavi, M., and Salazar, L. (2013). "Influence of Hydrogreen bioasphalt on viscoelastic properties of reclaimed asphalt mixtures." Transp. Res. Rec., 2371, 13-22.

Hansen, K., and Copeland, A. (2014). "Annual asphalt pavement industry survey on recycled materials and warm-mix asphalt usage: 2009-2013." National Asphalt Pavement Association, Lanham, MD.

Hong, F., Chen, D., and Mikhail, M. (2010). "Long-term performance evaluation of recycled asphalt pavement results from Texas." Transp. Res. Rec., 2180, 58-66.

Im, S., and Zhou, F. (2014). "Field performance of RAS test sections and laboratory investigation of impact of rejuvenators on engineering properties of RAP/RAS mixes." Rep. No. FHWA/TX-14/0-6614-3, Texas Transportation Institute, College Station, TX.

Johnson, E., and Olson, R. (2009). "Best practices for RAP use based on field performance." Rep. No. MN/RC 2009-15, Minnesota Dept. of Transportation, Maplewood, MN.

Kandhal, P. S., Rao, S., Watson, D., and Young, B. (1995). "Performance of recycled hot mix asphalt mixtures." NCAT Rep. No. 95-01, National Center for Asphalt Technology (NCAT), Auburn, AL.
Mallick, R., Tao, M., O'sullivan, K., and Frank, R. (2010). "Why not (use rejuvenator for) 100\% RAP recycling?" Proc., 89th TRB Annual Meeting, Transportation Research Board, Washington, DC.

Miller, J., and Bellinger, W. (2003). "Distress identification manual for the long-term pavement performance program." FHWA-RD-03-031.

Mogawer, W., Bennert, T., Austerman, A., and Ericson, C. (2015). "Investigating the aging mitigation capabilities of rejuvenators in high RAP mixtures using black space diagrams, binder rheology and mixture tests." Road Mater. Pavement Des., 16(2), in press.

O'Sullivan, K. (2011). "Rejuvenation of reclaimed asphalt pavement (RAP) in hot mix asphalt recycling with high RAP content." Master's thesis, Worcester Polytechnic Institute (WPI), Worcester, MA.

Tran, N., Taylor, A., and Willis, R. (2012). "Effect of rejuvenator on performance properties of HMA mixtures with high RAP and RAS contents." Rep. No. 12-05, National Center for Asphalt Technology (NCAT), Worcester, MA.

West, R., Kvasnak, A., Tran, N., Powell, B., and Turner, P. (2009). "Testing of moderate and high reclaimed pavement content mixes: Laboratory and accelerated field performance testing at the national center for asphalt technology test track." Transp. Res. Rec., 2126, 100-108.

West, R., Michael, J., Turochy, R., and Maghsoodloo, S. (2011). "Use of data from specific pavement studies experiment in the long-term pavement performance program to compare virgin and recycled asphalt pavements." Transp. Res. Rec., 2208, 82-89.

West, R., Willis, J. R., and Marasteanu, M. (2013). "Improved mix design, evaluation, and materials management practices for hot mix asphalt with high reclaimed asphalt pavement content." NCHRP Rep. No. 752, Transportation Research Board of the National Academies, Washington, DC.

Willis, R. (2012). "Reclaimed asphalt shingles characterization: Best practices." NCAT Rep. No. 13-07, Auburn, AL.

Zhao, S., Huang, B., Shu, X., Jia, X., and Woods, M. (2012). "Laboratory performance evaluation of warm-mix asphalt containing high percentages of reclaimed asphalt pavement." Transp. Res. Rec., 2294, 98-105.

Zhao, S., Huang, B., Shu, X., and Woods, M. (2013). "Comparative evaluation of warm mix asphalt containing high percentages of reclaimed asphalt pavement." Constr. Build. Mater., 44, 92-100.

Zhao, S., Huang, B., Shu, X., and Woods, M. (2015). "Quantitative characterization of binder blending how much recycled binder is mobilized during mixing?" Transp. Res. Rec., 2506, 72-80.

Zhou, F., Cindy, E., and Tom, S. (2014). "Literature review: Performance of RAP/RAS mixes and new direction." Rep. No. FHWA/TX-13/0-6738-1, Texas Transportation Institute, College Station, TX.

Zhou, F., Hu, S., Hu, X., Das, G., and Scullion, T. (2011). "High RAP mix design methodology with balanced performance." Research Rep. No. FHWA/TX-11/0-6092-2, Texas Transportation Institute, College Station, TX.

Zhou, F., Im, S., Morton, D., Lee, R., Hu, S., and Scullion, T. (2015). "Rejuvenator characterization, blend characteristics, and proposed mix design method." J. Assoc. Asphalt Paving Technol., 84, 675-704. 